\title{
Erythrocyte autoantibodies, autoimmune haemolysis, and myelodysplastic syndromes
}

\author{
R J SOKOL, S HEWITT, D J BOOKER \\ From the Regional Blood Transfusion Centre, Sheffield
}

SUMMARY Immunohaematological investigations were carried out in 46 patients with erythrocyte autoantibodies associated with myelodysplastic syndromes. Eight patients had refractory anaemia, 17 refractory anaemia with ring sideroblasts, 11 refractory anaemia with excess of blasts, four chronic myelomonocytic leukaemia, five refractory anaemia with excess of blasts in transformation and one could not be classified. Standard agglutination direct antiglobulin tests showed that the red cells were most often coated with IgG and C3d, though increased amounts of IgM or IgA were also found in 15 of 35 cases $(43 \%)$ when the more sensitive enzyme linked method was used. The IgG antibodies were predominantly of IgGl subclass. Clinically important autoimmune haemolysis occurred in 15 patients, and was of "warm", "cold," and "mixed" types in seven, four, and four cases, respectively: it is important to recognise its presence in view of the good response to treatment. The increased incidence of erythrocyte autoantibodies in myelodysplastic syndromes is thought to be one manifestation of disturbed immune homeostasis.

The myelodysplastic syndromes are a group of acquired disorders which usually occur in middle or later life and result from clonal abnormalities of haemopoietic stem cells. ${ }^{12}$ Attention has recently been drawn to the high incidence of erythrocyte autoantibodies in patients with myelodysplastic syndromes. ${ }^{3-5}$ By providing a serological reference service for a population of 4.7 million, ${ }^{6}$ the Trent Regional Blood Transfusion Centre is in a unique position to study a comparatively large number of such cases. We describe the immunohaematological findings in 46 patients with the association of myelodysplasia and red cell autoantibodies.

\section{Material and methods}

From January 11983 to June 301988 blood samples from 1756 patients with suspected autoimmune haemolysis, or in whom red cell autoantibodies had been found, were referred to this centre for serological investigation. The records of the 46 patients with confirmed myelodysplastic syndrome were critically examined. Particular attention was paid to the type of myelodysplasia (FAB classification),' the immunohaematological profile, and whether there was any clinically important autoimmune haemolysis. The latter was determined from the clinical and labors tory findings, including rate of transfusion, rate fall in haemoglobin concentrations, reticulocyt count, blood and marrow film appearances, and measurements of red cell life span, serum haptoglobins, bilirubin concentration and lactic de- $\frac{\mathbb{Q}}{\mathscr{Q}}$ hydrogenase activity.

The investigations carried out at this centre included direct antiglobulin tests (DAGT) using agglutination and enzyme linked methods, examination of red cell autoantibodies in serum and eluates, and detection of concomitant alloantibodies: full details have been $\frac{8}{0}$ described elsewhere. ${ }^{6-9}$ The incidence of myelodysplastic syndromes in the Trent Region was obtained from the referring hospitals and from the Leukaemia $ᄋ$ Research Fund Centre for Clinical Epidemiology (University of Leeds).

\section{Results}

Twenty of the patients were men and 26 women, ranging in age from 51 to 82 years and from 46 to $90 \mathrm{~N}$ years, respectively; the median ages were 71 and $75 \mathrm{\omega}$ years.

Patient details are given in the table. Eight patients $\stackrel{\varphi}{\varnothing}$ had refractory anaemia (RA), 17 refractory anaemia $\mathbb{D}$ with ring sideroblasts (RARS), 11 refractory anaemia ${ }^{+}$ with excess of blasts (RAEB), four chronic 0 myelomonocytic leukaemia (CMML), five refractory 
Erythrocyte autoantibodies and myelodysplastic syndrome

Table Results of immunohaematological studies on patients with myelodysplastic syndromes

Increased red cell bound proteins as shown by DAGT

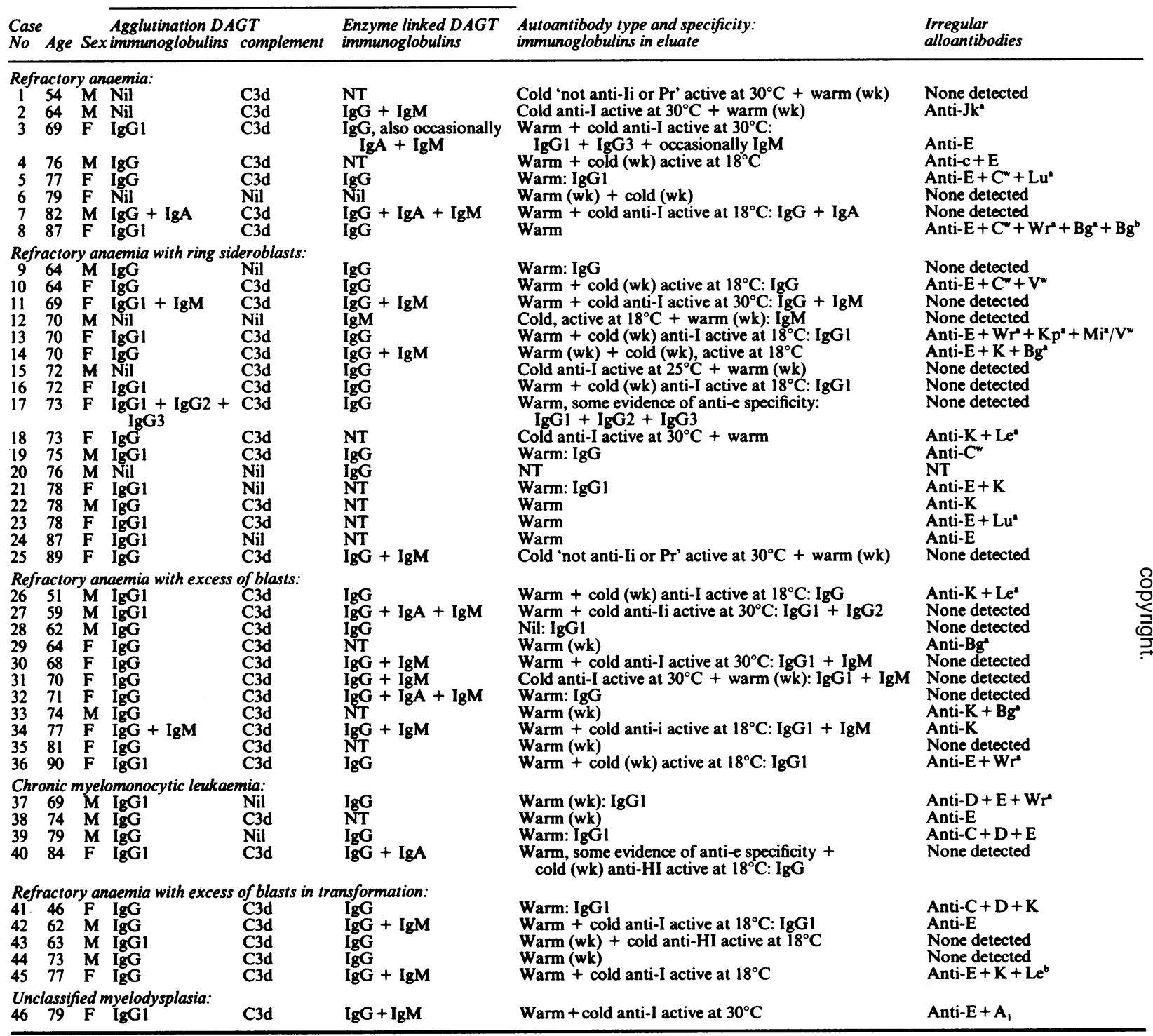

DAGT $=$ direct antiglobulin test, $\mathrm{NT}=$ not tested, $(\mathrm{wk})=$ antibody weakly reacting

anaemia with excess of blasts in transformation (RAEB-t) and one patient had myelodysplasia which could not be classified.

Clinically important autoimmune haemolysis occurred in 15 patients and was classified as "warm," "cold," and "mixed" types, depending on the reaction characteristics of the autoantibodies (table). ${ }^{610}$ Three patients with "warm" autoimmune haemolysis had cold agglutinins detectable at $18^{\circ} \mathrm{C}$, and in three patients with the "cold" type, weak reacting warm autoantibodies were also found. Immune mediated haemolysis was possibly present in a further 12 subjects, but not in the remaining 19 .

Almost all patients had been given multiple transfusions of blood. Only four had not been transfused and the transfusion history of one was unknown. 
Fifteen of the women had been pregnant, while the obstetric history of the other 11 could not be obtained.

Polyclonal increases of serum gammaglobulins were seen in $21(46 \%)$ patients and homogeneous bands were evident on electrophoresis in four $(8.5 \%)$ cases.

Autoantibodies to leucocytes and platelets were found in nine patients out of the 11 tested, while alloantibodies were detected in 13 subjects but not in four.

The overall incidence of new cases of myelodysplastic syndromes was 2.4 per 100000 of the population per year; it increased noticeably with age, the figure being $11 \cdot 1$ for those over 60 years.

\section{Discussion}

Forty six patients with the recently recognised association of erythrocyte autoantibodies, autoimmune haemolysis, and myelodysplastic syndromes were seen over 66 months. This association was seen in about $7 \%$ of patients with primary myelodysplasia and accounted for $2.6 \%$ of cases with erythrocyte autoantibodies referred during this time. The age range, with $87 \%$ being over 60 , was similar to that of other studies. ${ }^{211-15}$

Autoantibodies were found in all types of myelodysplasia (table). The classification was made at the time of referral and did not imply static biological entities as change to a more malignant form occurred in several patients. For this reason, no decision could be made regarding the tendency towards the formation of autoantibody in any particular type of myelodysplastic syndrome.

The agglutination DAGT showed that IgG and C3d most often coated the red cells, though in 15 of 35 patients $(43 \%)$ increased amounts of $\operatorname{IgM}$ or $\operatorname{IgA}$ could also be shown using the more sensitive enzyme linked DAGT (table) ${ }^{8}$ In 22 out of 25 cases IgGl was the only subclass of IgG present (table). The proportion of cases with a positive DAGT varied in other studies of myelodysplastic syndromes, with figures of five out of $134,{ }^{4}$ eight of $98,{ }^{3}$ and eight of $37^{5}$ being reported-a far higher incidence, as is $7 \%$ in our present study, than that for the general population of similar age. ${ }^{16}$ Compared with our series, more cases had solely IgG or complement bound to their cells, but only agglutination DAGTs had been used. ${ }^{3-5}$

In the 15 patients with firm evidence of autoimmune haemolysis the diagnosis had usually been suspected on finding difficulty in compatibility testing, a positive DAGT, strongly reacting autoantibodies, increased transfusion requirements not related to disease progression, reticulocytosis and low haptoglobin concentrations. Similar presenting features were noted in other reports. ${ }^{41718}$ When haemolysis was severe, diagnosis was not usually difficult, but in some cases the evidence was insufficient to determine whether clinically important immune mediated erythrocyte destruction was occurring. Measurement of red cell life span may be unhelpful because it is known to be shortened in most patients with myelodysplasia. ${ }^{.1}$ The finding of reticulocytosis can be of value, however, as reticulocyte counts are usually normal or reduced in myelodysplastic syndromes. ${ }^{212}$ It is important to diagnose autoimmune haemolysis in such patients as there is a good response to treatment and consequent improvement in well-being; in some cases an empirical trial of suitable treatment, such as prednisolone, may be warranted.

The increased incidence of erythrocyte autoantibodies in myelodysplastic syndromes may be one manifestation of disturbed immune homeostasis. Others include polyclonal increases in gammaglobulins (seen in $46 \%$ of our patients) in about $32 \%$ of patients with myelodysplasia generally, ${ }^{313}$ and in $66 \%$ of 35 cases of chronic myelomonocytic leukaemia $^{19}$ : monoclonal gammopathies were present in $8.5 \%$ of our cases and in $12 \%$ in other series. ${ }^{313} \mathrm{~A}$ reduction in number and function of $T$ cells (particularly $T$ helper) has also been found, together with abnormalities of natural killer and B cells. ${ }^{21520-22}$ The immune dysfunction in myelodysplastic syndromes may be related to the large number of blood transfusions, to non-specific stimulation of B lymphocytes by substances released from mononuclear phagocytes, or to the clonal defect causing activation of previously silent cell lines. ${ }^{3-5}$

Red cell alloantibodies were found in 26 patients $(57 \%)$; this was not surprising in view of the history of multiple transfusions in all but four, and pregnancies in at least 15 of the 26 women. Anti-E and anti-K occurred most frequently, either alone or in combination with other alloantibodies (table). A similar pattern has been reported in other studies of patients with erythrocyte autoantibodies, though concomitant alloantibodies were less common. ${ }^{9232}$ Most of the patients had been transfused elsewhere, and had our policy of giving Kell negative blood of matched $R h$ phenotype been followed, ${ }^{9}$ alloimmunisation would have been less common.

Leucocyte and platelet antibody investigations were carried out in a few instances. The high incidence of both auto- and allo- antibodies was not unexpected in view of the probable disturbed immune homeostasis and the histories of pregnancies and multiple transfusions. These investigations were made either because of cytopenia or, more commonly, following a febrile transfusion reaction.

We thank Drs G Bardhan, M J Brown, R A Cartwright, E A French, M L Ghosh, $R$ M Hutchinson, P A E Jones, E C M Logan, D C Mitchell, V Mitchell, D 
R Prangnell, S Sobolewski, K R Speed, R M Stewart, P C Taylor, J G Tetley, D A Winfield, J K Wood and P J Wyld for providing clinical details and Mrs P Burke for secretarial assistance.

\section{References}

1 Bennett JM. Classification of the myelodysplastic syndromes. Clin Haematol 1986;15:909-23.

2 Jacobs A, Clark RE. Pathogenesis and clinical variations in the myelodysplastic syndromes. Clin Haematol 1986;15:925-51.

3 Mufti GJ, Figes A, Hamblin TJ, et al. Immunological abnormalities in the myelodysplastic syndromes. I. Serum immunoglobulins and autoantibodies. $\mathrm{Br} J$ Haematol 1986;63:143-7.

4 Martin-Vega C, Massuet L, Julia A, et al. Autoimmune hemolytic anaemia (AIHA) in myelodysplastic syndromes (MS). In: Proceedings of the $X X$ congress of the International Society of Blood Transfusion in association with the British Blood Transfusion Society. London, 1988. Manchester: British Blood Transfusion Society, 1988:81.

5 Seitanides B, Antonopoulou A, Karabelis A. Immunological abnormalities i- -yelodysplastic syndrome. J Clin Pathol 1988;41:922-5.

6 Sokol RJ, Hewitt S, Stamps BK. Autoimmune haemolysis: an 18year study of 865 cases referred to a regional transfusion centre. Br Med J 1981;282:2023-7.

7 Sokol RJ, Hewitt S, Stamps BK. Erythrocyte autoantibodies, autoimmune haemolysis and pregnancy. Vox Sang 1982;43:169-76.

8 Sokol RJ, Hewitt S, Booker DJ, et al. An enzyme-linked direct antiglobulin test for assessing erythrocyte bound immunoglobulins. J Immunol Methods 1988;106:31-5.

9 Sokol RJ, Hewitt S, Booker DJ, et al. Patients with red cell autoantibodies: selection of blood for transfusion. Clin Lab Haematol 1988;10:257-64.

10 Sokol RJ, Hewitt S, Stamps BK. Autoimmune haemolysis: mixed warm and cold antibody type. Acta Haematol 1983;69:266-74.

11 Cazzola M, Barosi G, Berzuini C, et al. Quantitative evaluation of erythropoietic activity in dysmyelopoietic syndromes. $\mathrm{Br} J$ Haematol 1982;50:55-62.
12 Juneja SK, Imbert M, Jouault $H$, et al. Haematological features of primary myelodysplastic syndromes (PMDS) at initial presentation: a study of 118 cases. J Clin Pathol 1983;36:1129-35.

13 Economopoulos T, Economidou J, Giannopoulos G, et al. Immune abnormalities in myelodysplastic syndromes. J Clin Pathol 1985;38:908-11.

14 Mufti GJ, Stevens JR, Oscier DG, et al. Myelodysplastic syndromes: a scoring system with prognostic significance. $B r J$ Haematol 1985;59:425-33.

15 Colombat PH, Renoux M, Lamagnere J-P, et al. Immunologic indices in myelodysplastic syndromes. Cancer 1988;61:1075-81.

16 Sokol RJ, Hewitt S. Autoimmune hemolysis: a critical review. CRC Crit Rev Oncol Hematol 1985;4:125-54.

17 Sacher RA, McGinniss MM, Shashaty GG, et al. The occurrence of an auto-immune hemolytic anemia with anti-U specificity in a patient with myelodysplastic syndrome. Am J Clin Pathol 1982;77:356-9.

18 Longster GH, Johnson E. IgM anti-D as auto-antibody in a case of "cold" auto-immune haemolytic anaemia. Vox Sang 1988;54:174-6.

19 Solal-Celigny P, Desaint B, Herrera A, et al. Chronic myelomonocytic leukaemia according to FAB classification: analysis of 35 cases. Blood 1984;63:634-8.

20 Bynoe AG, Scott CS, Ford P, et al. Decreased T helper cells in the myelodysplastic syndromes. Br J Haematol 1983;54:97-102.

21 Colombat $\mathrm{P}$, Renoux M, Lamagnere JP, et al. T cell function in refractory anaemia with excess blasts. Br J Haematol 1984;56:171-80.

22 Greenberg PL. Biologic nature of the myelodysplastic syndromes. Acta Haematol 1987;78(suppl 1):94-9.

23 Wallhermfechtel MA, Pohl BA, Chaplin H. Alloimmunization in patients with warm autoantibodies. A retrospective study employing three donor alloabsorptions to aid in antibody detection. Transfusion 1984;24:482-5.

24 Laine ML, Beattie KM. Frequency of alloantibodies accompanying autoantibodies. Transfusion 1985;25:545-6.

Requests for reprints to: Dr R J Sokol, Regional Blood Transfusion Centre, Longley Lane, Sheffield S5 7JN, England. 